\title{
Bazı Zeytin Çeşidi Yapraklarındaki Flavanol Miktarına Ağaç Yaşı, Çeşit ve Sulamanın Etkisi
}

\author{
Hakan ÇETINKAYA ${ }^{1}$ \\ ${ }^{1}$ Kilis 7 Aralık Üniversitesi, Ziraat Fakültesi, Bahçe Bitkileri Bölümü, 79000 Kilis \\ *Sorumlu yazar: hcetinkaya67@gmail.com
}

\begin{abstract}
Öz
Flavonoitler kimyasal yapıları ve biyolojik fonksiyonlarından dolayı bitki fizyolojisi ve sağlık açısından önemli bir gruptur. Bitkilerde bu bileşiklerin miktarı ve kompozisyonu yetiştirme tekniğine, çeşide, yetiştirildiği ekolojiye, sulamaya ve ürünün işleme şekillerine göre değişiklik göstermektedir. Zeytin bitkisinde bu maddelerin birçoğu sentezlenmektedir. Bu çalışmada, sulanan ve sulanmayan koşullarda iki farklı zeytin çeşidinin (Kilis Yağlık ve Gemlik) ve farklı yaşlardaki Kilis Yağlık çeşidi yapraklarının flavanol içerikleri yıl boyunca incelenerek çeşit, sulama ve yaş faktörlerinin etkileri belirlenmeye çalışılmıştır. Araştırma sonuçlarına göre Kilis Yağlık zeytin çeşidi yaprakları Gemlik zeytin çeşidi yapraklarına göre daha fazla flavanol içermektedir. Yaş faktörünün yapraklarda flavanol içeriğine önemli bir etkisi bulunmamıştır. Sulamanın etkisi yönünden değerlendirildiğinde ise sulanmayan koşullarda yapraklarda daha fazla flavanol sentezlenmiştir.
\end{abstract}

Anahtar Kelimeler: Flavanoit, Flavanol, Kilis Yağlık, Gemlik

\section{Effects of Tree Age, Cultivar and Irrigation on Flavanol Content of Some Olive Cultivar Leaves}

\begin{abstract}
Flavonoids are the important groups in terms of plant physiology and health due to their chemical structure and biological functions. The amount and composition of these compounds in plants vary according to growth techniques, cultivar, plant growing ecology, irrigation and crop processes. In this study, flavanol contents of leaves were examined throughout the year in two different olive cultivars (Kilis Yağlık and Gemlik) and Kilis Yağlık variety at different ages to determine the effects of variety, irrigation and age factors on irrigated and irrigated conditions. According to research results, flavanol content of Kilis Yağlık cultivar leaves were contain more flavanols in terms of compared to Gemlik cultivar. There was no important effect of the age factor on flavanol content in leaves. Considering the effect of irrigation, flavanols were more synthesized in leaves on non-irrigated conditions.
\end{abstract}

Key Words: Flavanoid, Flavanols, Kilis Yağlık, Gemlik

\section{Giriş}

Fenolik bileşikler, hidroksil grubu içeren bileşikler olup bu bileşikler bitkilerde pek çok farklı kimyasal sınıfa ayrılmaktadır. Bu bileşiklerin bitkilerde stres koşullarına karşı savunma mekanizması olarak normal gelişim süresince sentezlendiği belirtilmektedir
(Justesen ve ark., 1998). Bitkilerin büyük bir bölümünde su stresine karşı fenolik bileşiklerin miktarının artış göstermesi ve bitkide sekonder metabolitlerin sentezinin artması, bitkinin strese karşı verdiği cevap olarak düşünülmektedir (Nouraei ve ark., 2016; Quan ve ark., 2016; Varele ve ark., 
2016). Ayrıca birçok araştırmacı bu bileşiklerin antioksidan aktiviteden sorumlu olan bileşikler olduğunu belirtmişlerdir (RiceEvans ve ark., 1997).

Flavonoitler kimyasal yapıları ve biyolojik fonksiyonlarından dolayı fenolikler içinde çeşitliliği en fazla olan bir gruptur (Robards ve Antolovich, 1997). Son yillarda flavonoitlere olan ilginin artması serbest radikalleri önleyici özellikleri, sebze, meyve ve çay gibi tükettiğimiz yiyecek ve içeceklerde yaygın olarak bulunmaları, hücre çoğalmasını inhibe edici, enzim aktivitelerini düzenleyici, antibiyotik ve antiallerjen özellikleri nedeniyledir (Justesen ve ark., 1998; Shi ve ark., 2001; Virgili ve ark., 2003; Rasmussen, 2004; Coşkun, 2005). Günümüzde 4000 'in üzerinde farklı flavonoit çeşidi bulunmaktadır. Flavonoitler için farklı sınıflandırmalar mevcut olmasına karsın flavonlar, flavononlar, flavonoller, isoflavonoitler, antosiyaninler ve flavanlar olmak üzere 6 temel flavonoit sınıfı bildirilmektedir (Peterson ve Dwyer, 1998). $\mathrm{Bu}$ bileşiklerin belirlenmesi, saflaştırılması, sağlık üzerindeki etkilerinin ortaya çıkarılması, biyokimyasal özellikleri, sentez yolları ve mekanizmaları, bitkilerde özellikle meyve ve sebzelerin yetiştirilmesi, işlenmesi veya depolanması sırasındaki değişimleri ve bitki stres fizyolojisinde fonksiyonları gibi konular araştırıcılar tarafından yoğun olarak çalışılmaktadır (Hollman ve ark., 1996; Peterson ve Dwyer, 1998; Hollman ve ark., 1999).

Zeytin bitkisinde bu maddelerin pek çoğu sentezlenmekte olup sentezlenen en önemli fenolik bileşikler tirosol, oleuropein, hidroksitirosol, propanoik asit, kumarik asit, flavonoitler, luteolin ve apigenindir. Zeytinde bulunan fenolik bileşikler; bitkinin besinsel tat özelliklerini, zeytinin rengini, besin değerini, zeytinyağının kararlılığını, mikroorganizmalara karşı dayanıklıı̆ı̆ını etkiler. Zeytin içerdiği bu aktif fenollerden dolayı Akdeniz diyetinde önemli bir yeri vardır (Rosillo ve ark., 2015; Rosignoli ve ark., 2016). Ayrıca bu bölgede zeytin yaprağı ekstraktları halk ilacı olarak da kullanılmaktadır (Sifaoui ve ark., 2013). Halk arasında zeytinyağı; ülser, kas ağrıları, kalp hastalıkları, iştahsızık, eklem, diz ve kemik ağrıları, yara, deri yırtılmaları ve kesiklerde, saç dökülmesinde, cilt hastalıkları, güneş yanıklığı, yüksek ateş ve zatürre gibi hastalıklarının tedavisinde, yaprak ve gövdeden elde edilen ekstraktlar; solunum ve sindirim sistemi hastalıkları, ağız içi yaralar, mantar hastalıkları, egzama, nezle, grip, öksürük ve ses kısıklı̆ı, idrar yolları ve safra kesesi tedavisinde kullanılmaktadır (Kaplan ve Arıhan, 2017).

Zeytinde fenolik bileşiklerin miktarı ve konsantrasyonu (Tura ve ark., 2007), yetiştirildiği bölgenin ekolojisi ve iklimi (Kalua ve ark., 2005; Vinha ve ark., 2005), sulama (Tovar ve ark., 2001), hasat ve ürün işleme (Ranalli ve ark., 2001; Gomez ve ark., 2002) gibi tarımsal ve kültürel uygulamalara göre değişkenlik göstermektedir.

$\mathrm{Bu}$ çalışmada Kilis ekolojisinde yetiştiriciliği yapılan iki farklı zeytin çeşidinin (Kilis Yağlık ve Gemlik) ve farklı yaşlardaki Kilis Yağlık zeytin çeşidi yapraklarının sulanan ve sulanmayan koşullarda flavanol içerikleri yıl boyunca incelenerek çeşit, sulama ve yaş faktörlerinin etkileri belirlenmeye çalışılmıştır.

\section{Materyal ve Metot}

\section{Bitki Materyali}

Çalışma Kilis ekolojik koşullarında gerçekleştirilmiştir. Bitki materyali olarak çeşitler arasındaki farklııkları belirlemek amacıyla ortalama aynı yaşlarda iki farklı zeytin çeşidi (Kilis Yağlık ve Gemlik), yaşın 
etkisini belirlemek amacıyla da Kilis Yağlık çeşidinin 9 ve 65 yaşlarındaki ağaçları kullanılmıştır. Çalışma üç tekerrürlü yapılmış olup her tekerrür için on bitki kullanılmıştır. Ağaçlar kontrol (sulanan) ve doğal koşullar (sulanmayan) olmak üzere 2 farklı şekilde denemeye alınarak değerlendirilmiştir. Sulama Mayıs-Ekim ayları arasında damla sulama yöntemi ile yapılmıştır. Flavanol içeriği belirlenecek olan yaprak örnekleri sürgünlerin orta kısımlarından alınmıştır. Örnek alma işlemi yıl boyunca birer aylık periyotlarla düzenli şekilde yapıımıştır. Alınan yaprak örnekleri laboratuvara getirilerek, çeşme suyunda yıkandıktan sonra saf sudan geçirilmiş ve daha sonra kese kâğıtlarına konularak, $65 \pm 5^{\circ} \mathrm{C}$ ye ayarlı bir etüvde sabit ağırlığa ulaşıncaya kadar kurutulmuştur. Örnekler analiz edilinceye kadar oda sıcaklığında laboratuvarda muhafaza edilmiştir.

\section{Flavanol Içeriğinin Belirlenmesi}

Flavanol içeriği, kuersetin (Quercetine) referans bileşiği standart olarak kullanılarak hesaplanmıştır. Bu yöntem, 440 nm maksimum absorpsiyonlu kompleks oluşumuna dayanmaktadır.

$1 \mathrm{ml}$ metanollü örnek ekstreleri $(10 \mathrm{mg}$ $\left.\mathrm{ml}^{-1}\right), 1 \mathrm{ml}$ alüminyum triklorür (20 $\mathrm{mg} \mathrm{ml}^{-1}$ ) ve $3 \mathrm{ml}$ sodyum asetat $\left(50 \mathrm{mg} \mathrm{ml}^{-1}\right)$ ile karıştırıımıştır. 2.5 saatlik inkübasyondan sonra $440 \mathrm{~nm}$ 'de absorbansları okunmuştur. Kuersetinin metanollü solüsyonu da $0.5 \mathrm{mg}$ $\mathrm{ml}^{-1}$ ) $440 \mathrm{~nm}$ 'de absorbansı okunmuştur (Kumaran ve Karunakaran, 2007; AbdelHameed, 2009). Çalışma üç tekerrürlü yapılmıştır. Bitki ekstrelerindeki flavanol miktarı kuersetin eş değeri olarak hesaplanmıştır.

\section{Araştırma Bulguları ve Tartışma}

Araştırmada, Gemlik ve Kilis Yağlık zeytin çeşitleri yaprakları ile Kilis Yağlık zeytin çeşidinin yaşlı ve genç ağaçlarının yaprakları analiz edilerek elde edilen bulgular istatistiksel olarak değerlendirilmiştir. Elde edilen bulgulara göre flavanol içeriğine çeşit ve sulama faktörlerinin etkisi önemli bulunurken, yaş faktörünün içeriğe etkisi önemli bulunmamıştır. Ayrıca her iki grupta da dönemsel olarak içerikte farklılıklar belirlenmiştir.

\section{Flavanol Içeriğindeki Değişimler}

Kilis Yağlık ve Gemlik zeytin çeşitleri yapraklarının flavanol düzeylerinin mevsimsel ve sulanan/sulanmayan koşullardaki değişimi Çizelge 1'de gösterilmiştir.

Zeytin yapraklarının flavanol içeriğinin çeşit, sulama ve aylara göre değişimi istatistiksel olarak önemli bulunmuştur. Buna göre en yüksek flavanol miktarı sulanmayan Gemlik çeşidinde Temmuz ayında (2.28 mg g' $\left.{ }^{1}\right)$, en düşük miktar ise sulanmayan Gemlik çeşidinde Şubat ayında $\left(0.10 \mathrm{mg} \mathrm{g}^{-1}\right)$ elde edilmiştir. Mevsimsel olarak ise yapraklarda en yüksek flavanol miktarı $1.88 \mathrm{mg} \mathrm{g}^{-1}$ ile Temmuz ayında, en düşük $0.34 \mathrm{mg} \mathrm{g}^{-1}$ ile Şubat ayında görülmüştür. Kilis Yağlık çeşidinde daha fazla flavanol (1.02 $\mathrm{mg} \mathrm{g}^{-1}$ ) sentezlenirken, sulanmayan koşullarda yine daha fazla flavanol (1.04 $\left.\mathrm{mg} \mathrm{g}^{-1}\right)$ elde edilmiştir (Şekil 1).

Kilis Yağlık çeşidinin farklı yaşlardaki ağaçlarının yapraklarındaki flavanol içeriğinin mevsimsel değişimi ve sulanan/sulanmayan koşullardaki değişimi Çizelge 2'de gösterilmiştir.

İstatistiksel olarak flavanol içeriğine yaş faktörünün etkisi önemli bulunmaz iken mevsimsel değişim ve sulama bakımından farklılıklar gözlemlenmiştir. Yaş etkisi değerlendirildiğinde, sulanan koşullarda daha yüksek flavanol (1.05 $\mathrm{mg} \mathrm{g}^{-1}$ ) elde 
edilirken, yıl boyunca aylar içinde en yüksek $1.73 \mathrm{mg} \mathrm{g}^{-1}$ ile ağustos ayında, en düşük 0.33 $\mathrm{mg} \mathrm{g}^{-1}$ ile mart ayında bulunmuştur (Şekil 2).

Zeytin ve zeytinyağı kalitesinin belirlenmesinde içerdiği fenolik madde miktarı başvurulan önemli kriterlerden birisidir. Zeytine özgü bir madde olan oleuropein gibi bazı özel fenoller lezzet, tat ve renk gibi kalite özelliklerini etkilemektedir (Turan, 2005). Ayrica bitkilerde bulunan fenolik bileşiklerin miktarı ve türüne hasat zamanı, genetik faktörler ve ağaç yaşı gibi birçok faktörün etkili olduğu bildirilmiştir (Ranalli ve ark., 2006).

Çizelge 1.Sulanan ve sulanmayan koşullarda zeytin çeşitleri yapraklarının flavanol içeriği $\left(\mathrm{mg} \mathrm{g}^{-1}\right)$ Table 1. Flavanol content of the leaves of olive cultivars grown in irrigated and non-irrigated conditions ( $\left.\mathrm{mg} \mathrm{g}^{-1}\right)$

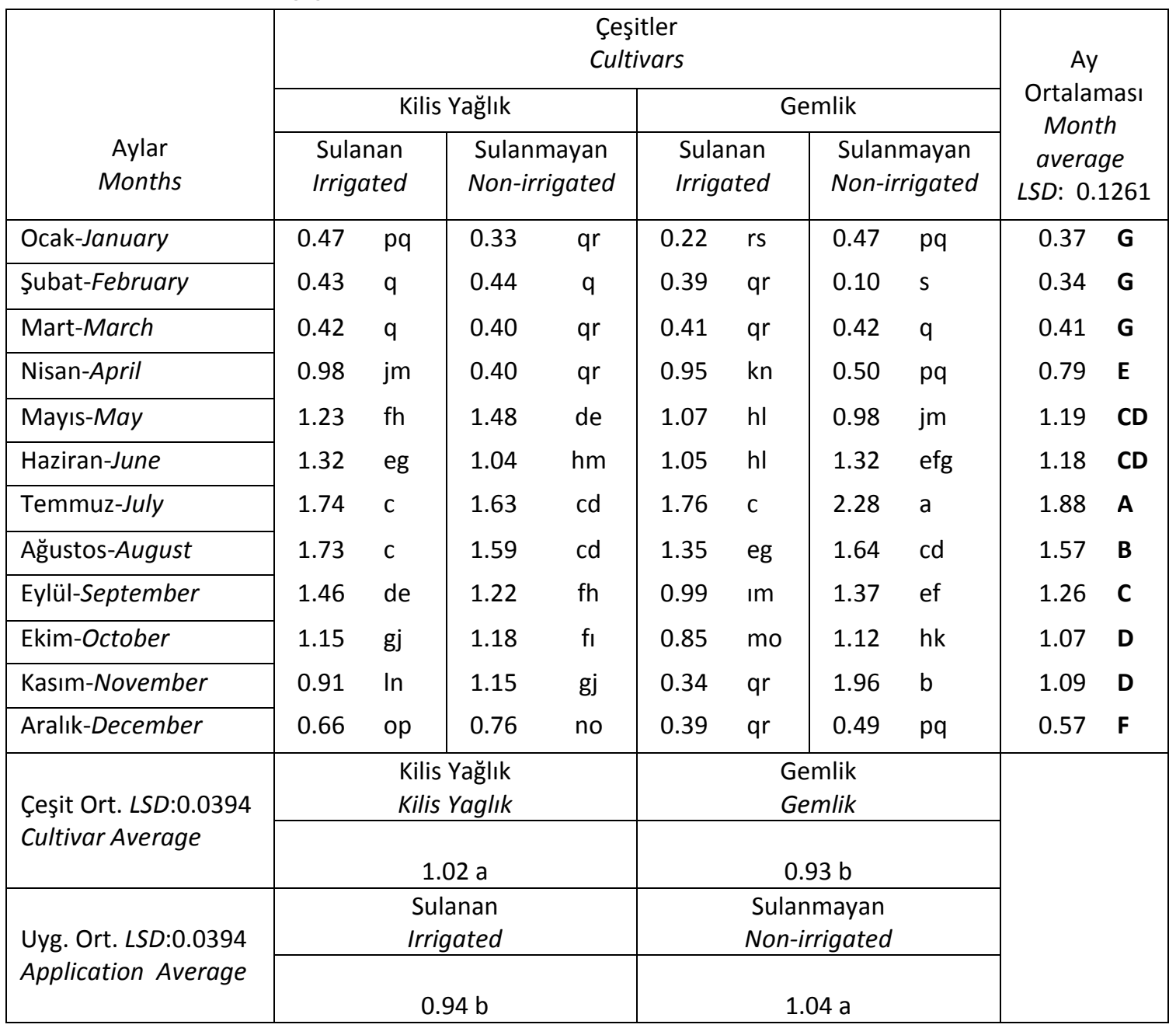


Çizelge 2. Sulanan ve sulanmayan koşullarda yetiştirilen farklı yaşlardaki Kilis Yağlık çeşidi yapraklarının flavanol düzeyleri $\left(\mathrm{mg} \mathrm{g}^{-1}\right)$

Table 2. Flavanol content of the leaves of different aged Kilis Yağlık cultivar grown in irrigated and non-irrigated conditions ( $\mathrm{mg} \mathrm{g}^{-1}$ )

\begin{tabular}{|c|c|c|c|c|c|c|}
\hline \multirow{3}{*}{$\begin{array}{l}\text { Aylar } \\
\text { Months }\end{array}$} & \multicolumn{6}{|c|}{ Kilis Yağlık } \\
\hline & \multicolumn{2}{|c|}{$\begin{array}{c}\text { Yaşlı } \\
\text { Old }\end{array}$} & \multicolumn{2}{|c|}{$\begin{array}{l}\text { Genç } \\
\text { Young }\end{array}$} & \multirow{2}{*}{\multicolumn{2}{|c|}{$\begin{array}{l}\text { Ay Ortalaması } \\
\text { Month average } \\
\text { LSD: } 0,06303\end{array}$}} \\
\hline & $\begin{array}{l}\text { Sulanan } \\
\text { Irrigated }\end{array}$ & $\begin{array}{l}\text { Sulanmayan } \\
\text { Non-irrigated }\end{array}$ & $\begin{array}{l}\text { Sulanan } \\
\text { Irrigated }\end{array}$ & $\begin{array}{l}\text { Sulanmayan } \\
\text { Non-irrigated }\end{array}$ & & \\
\hline Ocak-January & 0.320 & 0.620 & 0.470 & 0.330 & 0.435 & $\mathrm{H}$ \\
\hline Şubat-February & 0.517 & 0.470 & 0.430 & 0.440 & 0.464 & $\mathrm{H}$ \\
\hline Mart-March & 0.097 & 0.400 & 0.420 & 0.400 & 0.329 & 1 \\
\hline Nisan-April & 0.450 & 0.480 & 1.310 & 0.393 & 0.658 & G \\
\hline Mayıs-May & 1.390 & 1.120 & 1.230 & 1.480 & 1.305 & D \\
\hline Haziran-June & 1.350 & 1.420 & 1.320 & 1.040 & 1.283 & D \\
\hline Temmuz-July & 1.160 & 1.577 & 1.737 & 1.730 & 1.551 & B \\
\hline Ağustos-August & 2.090 & 1.520 & 1.730 & 1.590 & 1.732 & A \\
\hline Eylül-September & 1.870 & 1.590 & 1.460 & 1.220 & 1.535 & C \\
\hline Ekim-October & 1.290 & 1.140 & 1.150 & 1.180 & 1.190 & $E$ \\
\hline Kasım-November & 1.230 & 1.000 & 0.910 & 1.150 & 1.073 & $\mathrm{~F}$ \\
\hline Aralık-December & 0.620 & 0.410 & 0.660 & 0.750 & 0.610 & G \\
\hline \multirow{2}{*}{$\begin{array}{l}\text { Yaş Faktörü Ort. - ö.d. } \\
\text { Age Factor Average-n.s }\end{array}$} & \multicolumn{2}{|c|}{ Yaşlı-Old } & \multicolumn{2}{|c|}{ Genç-Young } & & \\
\hline & \multicolumn{2}{|c|}{1.005} & \multicolumn{2}{|c|}{1.022} & & \\
\hline \multirow{2}{*}{$\begin{array}{l}\text { Uyg. Ort. LSD:0.0139 } \\
\text { Application Average }\end{array}$} & \multicolumn{2}{|c|}{ Sulanan-Irrigated } & \multicolumn{2}{|c|}{ Sulanmayan-Non-irrigated } & & \\
\hline & \multicolumn{2}{|c|}{$1.050 \mathrm{a}$} & \multicolumn{2}{|c|}{$0.977 \mathrm{~b}$} & & \\
\hline
\end{tabular}

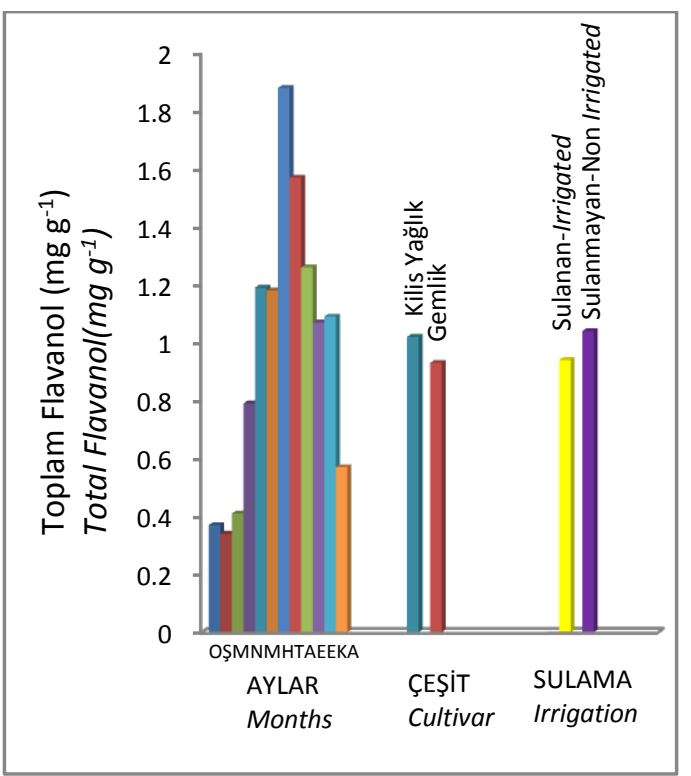

Şekil 1. Yaprakların dönem, çeşit ve sulamaya göre flavanol düzeyi

Figure 1. Flavanol content of the leaves according to periods, cultivars and irrigation

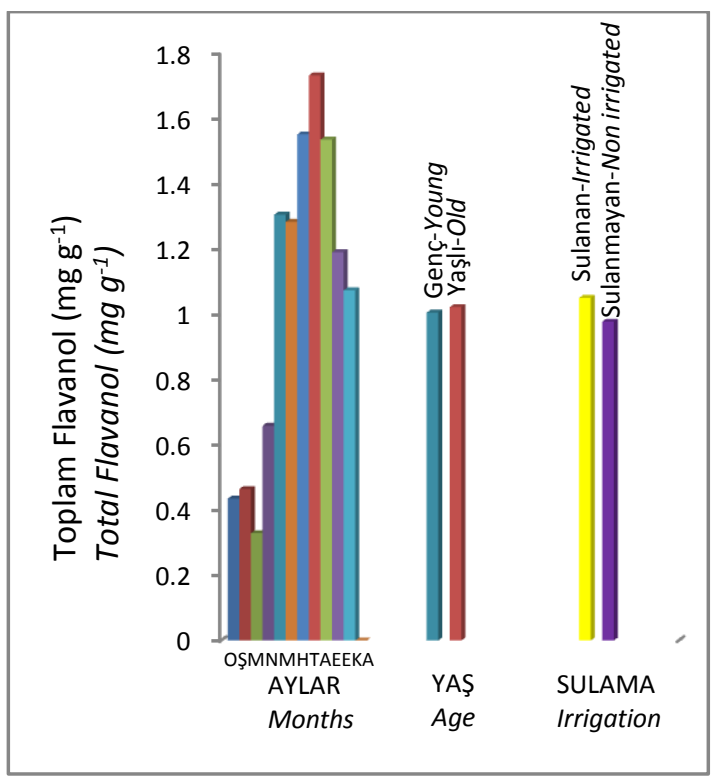

Şekil 2. Yaprakların dönem, yaş ve sulamaya göre flavanol düzeyi

Figure 2. Flavanol content of the leaves according to periods, age and irrigation 
Biyotik ve abiyotik stres koşullarına tepki olarak oluşan fenolik bileşikler, büyüme ve stres fizyolojisinde etkili olan bileşiklerdir (Ruiz ve ark., 2001; Doğan, 2005). Araştırmacılar, biyotik ve abiyotik faktörlere bağlı olarak fenolik bileşik sentez ve birikiminin uyarılabileceğini bildirmişlerdir. Buna karşın farklı tür ve genotipler üzerinde yapılan çalışmalarda da stres şiddetinin artmasıyla toplam fenolik madde içeriğinde azalmalar olabileceği de saptanmıştır (Dixon ve Paiva, 1995; Naczk ve ark., 2004). Bitkiler farklı stres faktörlerine karşı farklı tepkiler vermektedir. Özellikle su stresinde bitkilerin büyük çoğunluğunda fenolik bileşiklerin miktarı artmakta ve antioksidant aktivitelerinde artışlar görülmektedir. Bu da bu bileşiklerin bitkilerin savunma mekanizmasında rol oynadıklarını göstermesi bakımından önemlidir (Stagnari ve ark., 2014; Aninbon ve ark., 2016; Gharibi ve ark., 2016; Popoviç ve ark., 2016).

Stres faktörlerine karşı salisilik asit ve askorbik asit gibi bileşiklerin dışsal uygulaması sonucu fenolik bileşiklerin artması polifenollerin bitkideki rolü hakkında fikir vermektedir (Kabiri ve ark., 2014; Shafig ve ark., 2014).

\section{Sonuçlar}

Zeytin ve zeytinyağının karakterizasyonu ve tanımlanmasında fenolik bileşikler en önemli kimyasal parametrelerdendir. Hasat zamanı, hasat şekli ve zeytin çeşidine bağı olarak toplam fenolik madde içeriği değişiklik göstermektedir. Zeytin ve zeytinyağlarında fenolik maddeler biyolojik özelliklerini, dayanıklııı̆ını ve lezzetini etkilemektedir. Ayrıca fenolik bileşikler bitkilerin stres koşullarına vereceği cevap yönünden önemlidir.

Çalışma sonucunda çeşit ve yaş faktörleri bakımından zeytin yapraklarının flavanol miktarındaki değişimler istatistiksel olarak değerlendirilmiştir. Buna göre zeytin yapraklarının flavanol içeriğinin çeşit, sulama ve aylara göre değişimi istatistiksel olarak önemli bulunurken, yaş faktörünün etkisi önemli bulunmamıştır. Çeşit, sulama ve mevsimsel değişim değerlendirildiğinde en yüksek flavanol miktarı sulanmayan Gemlik çeşidinde temmuz ayında, en düşük miktar ise sulanmayan Gemlik çeşidinde şubat ayında elde edilmiştir. Mevsimsel olarak ise yapraklarda en yüksek flavanol miktarı temmuz ayında, en düşük şubat ayında görülmüştür. Kilis Yağlık çeşidinde daha fazla flavanol sentezlenirken, sulanmayan koşullarda yine daha fazla flavanol elde edilmiştir.

Yaş etkisi değerlendirildiğinde sulanan koşullarda daha yüksek flavanol elde edilirken, yıl boyunca aylar içinde ise en yüksek Ağustos ayında, en düşük mart ayında bulunmuştur.

Sonuç olarak zeytin yaprağındaki flavanol içeriğine sulama ve çeşit etkisi önemlidir. Flavanol gibi bitkilerdeki biyoaktif bileşiklerin miktarının ve çeşidinin belirlenmesi ve kuraklık ve stres mekanizmalarının aydınlatılması, bitki fizyolojisine, bitki yetiştiriciliği ve gıda teknolojisine önemli katkılar sağlayacaktır.

\section{Ekler}

Bu çalışma Kilis 7 Aralık Üniversitesi Bilimsel Araştırma Projeleri (BAP) birimi (2011/1/LTP/04 no'lu proje) tarafindan desteklenmiştir

\section{Kaynaklar}

Abdel-Hameed, E.S.S., 2009. Total phenolic contents and free radical scavenging activity of certain Egyptian Ficus species leaf samples. Food Chemistry, 114(4): 1271-1277. 
Aninbon, C., Jogloy, S., Vorasoot, N., Patanothai, A., Nuchadomrong, S., Senawong, T., 2016. Effect of end of season water deficit on phenolic compounds in peanut genotypes with different levels of resistance to drought. Food Chemistry, 196: 123-129.

Coskun, T., 2005. Fonksiyonel Besinlerin Sağlığımız Üzerine Etkileri. Çocuk Sağlığı ve Hastalıkları Dergisi, 48: 69-84.

Dixon, R.A., Paiva, N., 1995. Stress-induced phenylpropanoid metabolism. Plant Cell, 7: 1085-1097.

Doğan, M., 2005. Ceratophyllum demersum L.'de kadmiyum klorür, sodyum klorür ve bunların kombinasyonlarının fizyolojik ve morfolojik etkileri. Doktora Tezi, Çukurova Üniversitesi, Fen Bilimleri Enstitüsü, Adana, 137s.

Gharibi, S., Tabatabaei, B.E.S., Saeidi, G., Goli, S.A.H., 2016. Effect of drought stress on total phenolic, lipid peroxidation, and antioxidant activity of Achillea species. Applied Biochemistry and Biotechnology, 178(4): 796-809.

Gomez-Alonso, S., Salvador, M.D., Fregapane, G., 2002. Phenolic compounds profile of Cornicabra virgin olive oil. Journal of Agricultural and Food Chemistry, 50(23): 6812-6817.

Hollman, P.C.H., Buysman, M.P., Van Gameren, Y., Cnossen, E., de Vries, J., Katan, M., 1999. The sugar moiety is a major determinant of the absorption of dietary flavonoid glycosides in man. Free Radical Research, 31: 569-573.

Hollman, P.C.H., Hertog, M.G.L., Katan, M.B., 1996. Analysis and health effects of flavonoids. Food Chemistry, 57(1): 43-46.

Justesen, U., Knuthsen, P., Leth, T., 1998. Quantitative analysis of flavonols, flavones, and flavonones in fruits, vegetables and beverages by highperformance liquid chromatography with photodiode array and mass spectrometric detection. Journal of Chromatography A, 799: 101-110.

Kabiri, R., Nasibi, F., Farahbakhsh, H., 2014. Effect of exogenous salicylic acid on some physiological parameters and alleviation of drought stress in Nigella sativa plant under hydroponic culture. Plant Protection Science, 50(1): 43-51.

Kalua, C.M., Allen, M.S., Bedgood, D.R., Bishop, A.G., Prenzler, P.D., 2005. Discrimination of olive oils and fruits into cultivars and maturity stages based on phenolic and volatile compounds. Journal of Agricultural and Food Chemistry, 53(20): 8054-8062.

Kaplan, M., Arıhan, S.K., 2017. Antikçağdan Günümüze Bir Şifa Kaynağı: Zeytin ve Zeytinyağının Halk Tıbbında Kullanımı. DTCF Dergisi, 52(2): 1-15.

Kumaran, A., Karunakaran, R.J., 2007. Activityguided isolation and identification of free radical-scavenging components from an aqueous extract of Coleus aromaticus. Food Chemistry, 100: 356-361.

Naczk, M., Shahidi, F., 2004. Extraction and analysis of phenolics in food. Journal of Chromatography A, 1054 (1-2): 95-111.

Nouraei, S., Rahimmalek, M., Saeidi, G., Bahreininejad, B., 2016. Variation in seed oil content and fatty acid composition of globe artichoke under different irrigation regimes. Journal of the American Oil Chemists' Society, 93(7): 953-962.

Peterson, J., Dwyer, J., 1998. Flavonoids, dietary occurrence and biochemical activity. Nutrition Research, 18(12): 1995-2018.

Popovic, B.M., Stajner, D., Zdero-Pavlovic, R., Tumbas-Saponjac, V., CanadanovicBrunet, J., Orlovic, S., 2016. Water stress induces changes in polyphenol profile and antioxidant capacity in poplar plants (Populus spp.). Plant Physiology and Biochemistry, 105: 242-250.

Quan, N.T., Anh, L.H., Khang, D.T., Tuyen, P.T., Toan, N.P., Minh, T.N., Trung, K.H., 2016. Involvement of Secondary Metabolites in Response to Drought Stress of Rice (Oryza sativa L.). Agriculture, 6(2): 23.

Ranalli, A., Contento, S., Lucera, L., Di Febo, M., Marchegiani, D., Di Fonzo, V., 2006. Factors affecting the contents of iridoid oleuropein in olive leaves (Olea europaea L.). Journal of Agricultural and Food Chemistry, 54(2): 434-440.

Ranalli, A., Contento, S., Schiavone, C., Simone, N., 2001. Malaxing temperature affects volatile and phenol composition as well as other analytical features of virgin olive oil. European Journal of Lipid Science and Technology, 103(4): 228-238.

Rasmussen, S.E., 2004. Flavonoids and Cardiovascular Disease. "Alınmıştır: Functional Foods, In Cardiovascular Disease and Diabetes, (Ed) A. Arnoldi, CRC 
Press LLC, Boca Raton, Cambridge, England, 157-179pp.

Rice-Evans, C., Miller, N., Paganga, G., 1997. Antioxidant properties of phenolic compounds. Trends in Plant Science, 2(4): 152-159.

Robards, K., Antolovich, M., 1997. Analytical chemistry of fruit bioflavonoids: A review. The Analyst, 3: 122-130.

Rosignoli, P., Fuccelli, R., Sepporta, M.V., Fabiani, R., 2016. In vitro chemo-preventive activities of hydroxytyrosol: the main phenolic compound present in extra-virgin olive oil. Food and Function, 7(1): 301-307.

Rosillo, M.A., Sanchez-Hidalgo, M., Gonzalez-Benjumea, A., Fernandez-Bolanos, J.G., Lubberts, E., Alarcon-de-la-Lastra, C., 2015. Preventive effects of dietary hydroxytyrosol acetate, an extra virgin olive oil polyphenol in murine collagen-induced arthritis. Molecular Nutrition and Food Research, 59(12): 2537-2546.

Ruiz, J.M., Romero, L., 2001. Bioactivity of the phenolic compounds in higher plants. Studies in Natural Products Chemistry, 25: 651-681.

Shafiq, S., Akram, N.A., Ashraf, M., Arshad, A., 2014. Synergistic effects of drought and ascorbic acid on growth, mineral nutrients and oxidative defense system in canola (Brassica napus L.) plants. Acta Physiologiae Plantarum, 36(6): 1539-1553.

Shi, H., Noguchi, N., Niki, E., 2001. Introducing Natural Antioxidants. "Alınmıştır: In Antioxidants in Food, Practical Applications, (Ed) Pokorny, J., Yanishlieva, N., Gordon, M., CRC Press LLC, Boca Raton, Cambridge, England, 147-155pp.

Sifaoui, I., Lopez-Arencibia, A., Martín-Navarro, C.M., Chammem, N., Mejri, M., LorenzoMorales, J., Pinero, J.E., 2013. Activity assessment of Tunisian olive leaf extracts against the trophozoite stage of Acanthamoeba. Parasitology Research, 112(8): 2825-2829.

Stagnari, F., Galieni, A., Speca, S., Pisante, M., 2014. Water stress effects on growth, yield and quality traits of red beet. Scientia Horticulturae, 165: 13-22.

Tovar, M.J., Motilva, M.J., Romero, M.P., 2001. Changes in the phenolic composition of virgin olive oil from young trees (Olea europaea L. CV. Arbequina) grown under linear irrigation strategies. Journal of
Agricultural and Food Chemistry, 49(11): 5502-5508.

Tura, D., Gigliotti, C., Pedò, S., Failla, O., Bassi, D., Serraiocco, A., 2007. Influence of cultivar and site of cultivation on levels of lipophilic and hydrophilic antioxidants in virgin olive oils (Olea europaea L.) and correlations with oxidative stability. Scientia Horticulturae, 112(1): 108-119.

Turan, E., 2005. Sarı Ulak Tarsus Zeytin ve Siyah Çaydan Elde Edilen Fenolik Ekstraktların Antioksidan Etkilerinin Araştırılması, Yüksek Lisans Tezi, Çukurova Üniversitesi, Fen Bilimleri Enstitüsü, Adana, 49s.

Varela, M.C., Arslan, I., Reginato, M.A., Cenzano, A. M., Luna, M.V., 2016. Phenolic compounds as indicators of drought resistance in shrubs from Patagonian shrublands (Argentina). Plant Physiology and Biochemistry, 104: 81-91.

Vinha, A.F., Ferreres, F., Silva, B.M., Valentao, P., Gonçalves, A., Pereira, J.A., Andrade, P.B., 2005. Phenolic profiles of Portuguese olive fruits (Olea europaea L.): Influences of cultivar and geographical origin. Food Chemistry, 89(4): 561-568.

Virgili, F., Scaccini, C., Packer, L., Rimbach, G., 2003. Nutritional Phenolics and Cardiovascular Disease. "Alınmıştır: In Phytochemical Functional Foods, (Ed) I. Johnson, G. Williamson, Woodhead Publishing Limited and CRC Press LLC, Boca Raton, Cambridge, England, 5-14pp. 